\title{
Morphological and Spectroscopic Study of an Apatite Layer Induced by Fast-Set Versus Regular-Set EndoSequence Root Repair Materials
}

\author{
Sawsan T. Abu Zeid ${ }^{1,2, *}$, Ruaa A. Alamoudi ${ }^{1}$, Ensanya A. Abou Neel ${ }^{3,4,5}$ and \\ Abeer A. Mokeem Saleh ${ }^{1}$ \\ 1 Endodontic Department, Faculty of Dentistry, King Abdulaziz University, Jeddah 21589, Saudi Arabia; \\ ralamoudi1@kau.edu.sa (R.A.A.); aasaleh@kau.edu.sa (A.A.M.S.) \\ 2 Endodontic Department, Faculty of Dentistry, Cairo University, Cairo 12613, Egypt \\ 3 Division of Biomaterials, Restorative Dentistry Department, Faculty of Dentistry, King Abdulaziz University, \\ Jeddah 21589, Saudi Arabia; eabouneel@kau.edu.sa \\ 4 Biomaterials Department, Faculty of Dentistry, Tanta University, Tanta 31512, Egypt \\ 5 UCL Eastman Dental Institute, Biomaterials and Tissue Engineering Division, 256 Gray's Inn Road, \\ London WC1X 8LD, UK \\ * Correspondence: sawsanabuzeid55@hotmail.com; Tel.: +966-5-0952-8971
}

Received: 3 October 2019; Accepted: 5 November 2019; Published: 8 November 2019

\begin{abstract}
This study aimed to evaluate the morphology and chemistry of an apatite layer induced by fast-set versus regular-set EndoSequence root repair materials using spectroscopic analysis. Holes of a $4 \mathrm{~mm}$ diameter were created in the root canal dentin, which were filled with the test material. Fetal calf serum was used as the incubation medium, and the samples incubated in deionized water were used as controls. The material-surface and material-dentin interfaces were analyzed after 28 days using Raman and infrared spectroscopy, scanning electron microscopy/energy dispersive X-ray, and $X$-ray diffraction. After incubation in fetal calf serum, both materials formed a uniform layer of calcium phosphate precipitate on their surfaces, with the dentinal interface. This precipitated layer was a combination of hydroxyapatite and calcite or aragonite, and had a high mineral maturity with the regular-set paste. However, its crystallinity index was high with the fast-set putty. Typically, both consistencies (putty and paste) of root repair material have an apatite formation ability when they are incubated in fetal calf serum. This property could be beneficial in improving their sealing ability for root canal dentin.
\end{abstract}

Keywords: apatite formation; bioactivity; $\mathrm{Ca} / \mathrm{P}$ and $\mathrm{CO}_{3} / \mathrm{PO}_{4}$ ratios; root repair; spectroscopy analysis

\section{Introduction}

Root perforation is an undesired iatrogenic endodontic mishap. It may occur on a lateral root surface or in a furcal area. It provides direct communication between pulp space and periodontal tissue, and leads to a loss of root integrity and endodontic failure [1]. Since the early 1990s, mineral trioxide aggregates (MTA) have been a popular material in root repair [2]. The success of perforation repair is dependent on the material's ability to seal the perforation defect [3].

Different root repair materials have been introduced into the market to overcome the drawbacks of traditional mineral trioxide aggregates, such as the long setting time and poor handling. EndoSequence root repair materials (ERRM) are mainly composed of calcium silicate and calcium phosphate [4]. As an alternative to MTA, calcium silicate-based materials have been considered bioactive, which is the material's ability to form an apatite-like precipitate on its surface when brought into contact with tissue fluids. This precipitation occurs as a result of the interaction of ions released from the material 
with the surrounding tissue fluid [5]. Apatite precipitation can improve the sealing ability of these materials when occurring at a material-dentin interface $[5,6]$.

Different formulas of ERRM have been launched to improve their application. ERRM are available with different consistencies: fast-set putty with a heavy consistency and regular-set paste with a light consistency. These different consistencies exhibit variable physical behavior as they have various particle sizes [7]. Fast-set putty exhibits an adhesive failure mode and greater displacement resistance than regular-set paste [7]. Therefore, this difference may affect their chemical behavior and morphology when immersed in simulated tissue fluid.

There are few studies that have evaluated the surface of EndoSequence putty when immersed in different solutions. They have assessed the surface morphology of the material and apatite precipitation by scanning electron microscopy [8,9]. The surface topography of putty varied, according to the fluid in which the material was incubated. The unset putty material exhibited a smooth surface topography. After setting, the putty showed a smooth topography, with clusters of elongated crystals when incubated in water. Globular deposits, however, were found when set putty was incubated in Hank's Balanced Salt Solution [8]. Another study evaluated the surface nucleation of TotalFill putty and paste formula. Both formulas showed different chemical behaviors [10].

No study has evaluated the material-dentin interface, which is a significant parameter for detecting the sealing ability of any material.

This study evaluates the morphology and chemistry of an apatite layer induced by fast-set versus regular-set EndoSequence root repair materials after incubation in simulated tissue fluid (e.g., fetal calf serum) [11]. The material, material-dentin, and dentin surfaces were evaluated using scanning electron microscopy/energy dispersive X-ray (SEM/EDX), Raman Spectroscopy, Fourier transform infrared spectroscopy (FTIR), and X-ray diffraction (XRD) $[6,12,13]$.

The proposed null hypothesis states that "there is no difference between the fast-set putty and regular-set paste root repair materials in terms of apatite formation".

\section{Materials and Methods}

EndoSequence Brasseler root repair materialBC RRM fast-set putty and regular-set paste root repair materials (Brasseler, Boulevard, Savannah, GA, USA) were used for this study.

\subsection{Specimen Preparation}

After getting ethical approval (\#063-04-18), human, freshly extracted, single-rooted premolars were used for this study. The longitudinal root sections $(n=12)$ were randomly divided into two groups ( $\mathrm{n}=6 \mathrm{each}$ ) [10]. Two holes of a $4 \mathrm{~mm}$ diameter, representing lateral root perforation, were prepared in each root section and filled with EndoSequence fast-set putty or regular-set paste. They were then wrapped with gauze moistened with deionized water and incubated at $37^{\circ} \mathrm{C} / 100 \%$ relative humidity for three days, until the complete setting of the material. They were then subdivided into two groups ( $\mathrm{n}=3$ each): the experimental and control group. The samples of the experimental group were incubated in fetal calf serum (FCS, Gibco, Life Technology, Carlsbad, CA, USA) for 28 days, with the FCS replaced at 3 day intervals, while the samples of the control group were incubated in deionized water. At the end of the experiment, the samples were washed with deionized water and left to dry for $48 \mathrm{~h}$ in an incubator. They were then analyzed with Raman Spectroscopy, Fourier transform infrared spectroscopy (FTIR), and a scanning electron microscope/energy dispersive X-ray (SEM/EDX).

Discs $(\mathrm{n}=8)$ of a $10 \mathrm{~mm}$ diameter and $3 \mathrm{~mm}$ height from EndoSequence fast-set putty and regular-set paste root repair materials were prepared and left to set as described above. These discs were divided into two groups ( $n=4$ each); two were left in FCS for 28 days and the other two were used as controls (incubated in deionized water). These discs were analyzed with X-ray diffraction (XRD). 


\subsection{Raman Spectroscopy}

The spectra of the materials and the material-dentin interface were obtained using Micro-Raman Spectroscopy (Senterra, Bruker, Berlin, Germany) associated with a laser driver (Nd-YAG dropped AIY Jernet), CCD detector (Bruker, Germany), and microscope with a confocal pinhole. Three spectra from different locations were obtained for each sample. The ratio of $965 \mathrm{Ap} / 916 \mathrm{CaWO} \mathrm{cm}^{-1}$ band intensity as an indication of the thickness of the apatite layer at the material-surface and the material-dentin interface was calculated [14-16]. The mineral maturity was also considered, and it was calculated as the area ratio of the apatitic phosphate band detected at $1030 \mathrm{~cm}^{-1} /$ non-apatitic phosphate band detected at $1110 \mathrm{~cm}^{-1}[14-16]$.

\subsection{Fourier Transform Infrared Spectroscopy}

The spectra of the material-surface and the material-dentin interface were obtained using Fourier Transform Infrared Spectroscopy (FTIR-6100, Jasco, Tokyo, Japan). The spectra were recorded in the $4000-400 \mathrm{~cm}^{-1}$ range and at a $1 \mathrm{~cm}^{-1}$ resolution. Three spectra from different locations were obtained for each sample. The carbonate/phosphate $\left(\mathrm{CO}_{3} / \mathrm{PO}_{4}\right)$ ratio, which is an indication of carbon substitution for phosphate, was calculated from the integrated area under carbonate $\left(\mathrm{v} \mathrm{CO}_{3}\right)$ and phosphate ( $\vee 1 \vee 3 \mathrm{PO}_{4}$ ) bands at $830-890$ and $900-1200 \mathrm{~cm}^{-1}$, respectively [13,17]. The crystallinity index, an indication of the crystal perfection, was calculated using the asymmetric stretching vibration of the phosphate bands at 604 and $560 \mathrm{~cm}^{-1}[14,18]$.

\subsection{Scanning Electron Microscope/Energy Dispersed X-ray Analysis (SEM/EDX)}

A scanning electron microscope/energy dispersed X-ray analysis (Quanta 250 Field Emission Gun attached, FEI Company, Eindhoven, The Netherlands, UK) was used to study the morphology and elemental composition of each sample. Three EDX readings were obtained from three different areas across the sample. From the EDX, the calcium/phosphate $(\mathrm{Ca} / \mathrm{P})$ ratio was calculated from the atomic percentage.

\subsection{X-ray Diffraction (XRD)}

The discs of each material were milled into a fine powder and analyzed by XRD (Empyrean, Analytical 2010, Eindhoven, The Netherlands, UK).

\subsection{Statistical Analyses}

Statistical analysis was performed using a Student t-test. SPSS software (Version 16, Munich, Germany) was used at the significance level of $5 \%$.

\section{Results}

\subsection{Raman Spectroscopy}

The Raman spectra of EndoSequence fast-set putty and regular-set paste, kept in deionized water for 28 days, revealed nearly identical bands, which varied in their intensities (Figure 1a). The bands include $v 3$ carbonate near $1400 \mathrm{~cm}^{-1}$ [19]; calcite or aragonite at $1088 \mathrm{~cm}^{-1}$ [12,20-22]; sulfate $\left(v 1 \mathrm{SO}_{4}{ }^{2-}\right.$ and $\left.v 2 \mathrm{SO}_{4}{ }^{2-}\right)$ at $1005 \mathrm{~cm}^{-1}$ and $421 \mathrm{~cm}^{-1}$, respectively [22,23]; phosphate $\left(v 1 \mathrm{PO}_{4}{ }^{3-}\right)$ at 903-990 $\mathrm{cm}^{-1}$ [24]; crystalline silicate $\left(\mathrm{SiO}_{4}{ }^{4-}\right)$ at $857 \mathrm{~cm}^{-1}$ [23]; and $v 3 \mathrm{SiO}_{4}{ }^{4-}$ at 535 and $520 \mathrm{~cm}^{-1}$ [22]. The intensities of the $v 1 \mathrm{PO}_{4}{ }^{3-}$ band at $927 \mathrm{~cm}^{-1}$ and $v 4 \mathrm{SO}_{4}{ }^{2-}$ at 633 and $614 \mathrm{~cm}^{-1}$ were higher with the EndoSequence fast-set putty than with the regular-set paste. Aluminum constituents at $714 \mathrm{~cm}^{-1}$ [25]; tantalum oxide around 660,633, 613, 331, 252, and $197 \mathrm{~cm}^{-1}$ [26,27]; zirconia at 475 and $182 \mathrm{~cm}^{-1}$ [16]; organic bands of amide I ( $\mathrm{C}=\mathrm{O}$ stretch) at $1666 \mathrm{~cm}^{-1}$; and amide III $(\mathrm{N}-\mathrm{H})$ at $1230-1289 \mathrm{~cm}^{-1}$ [28] were also detected in the spectra of both materials. 
(a) Materials incubated in deionized water for 28 days

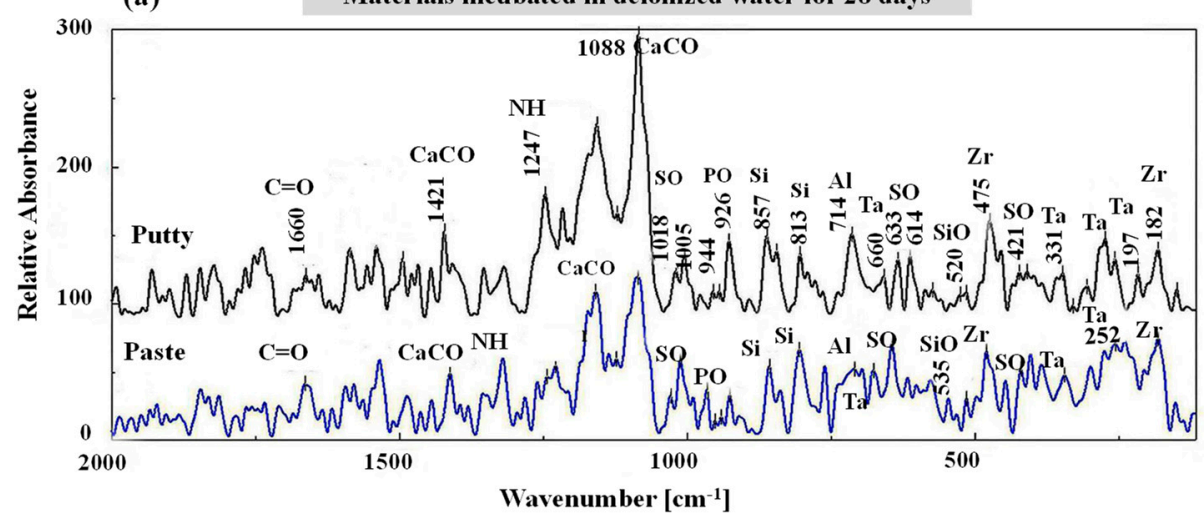

Materials incubated in FCS for 28 days
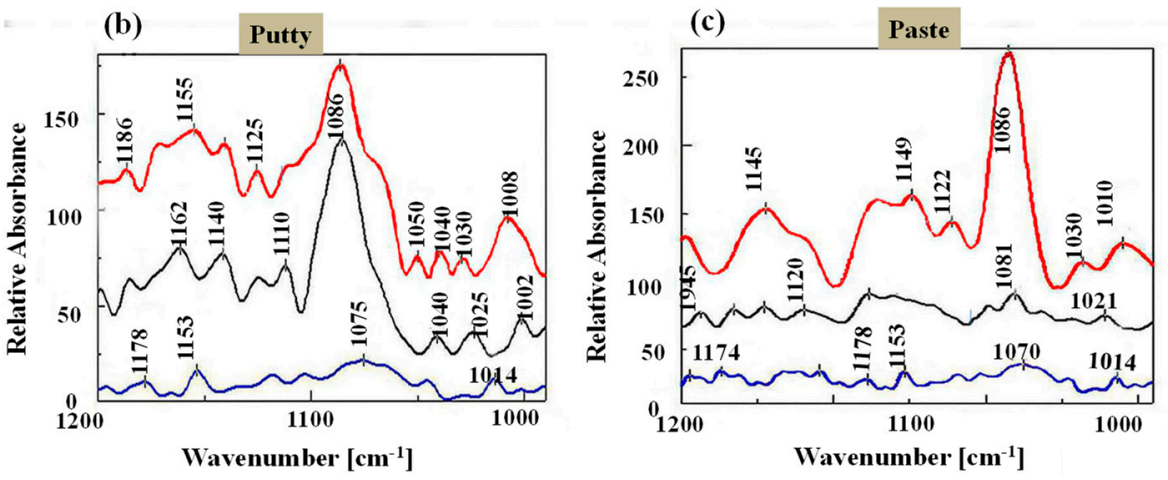

(d)

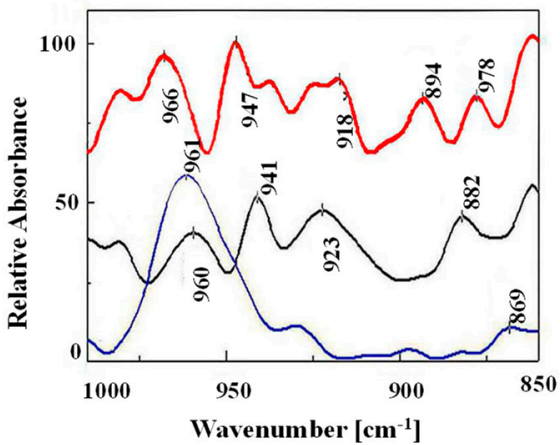

(e)

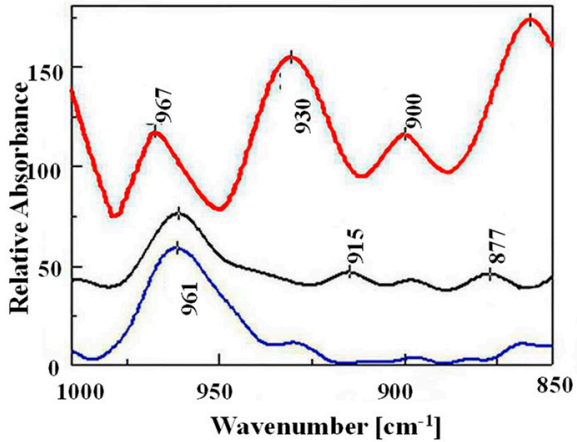

(g)
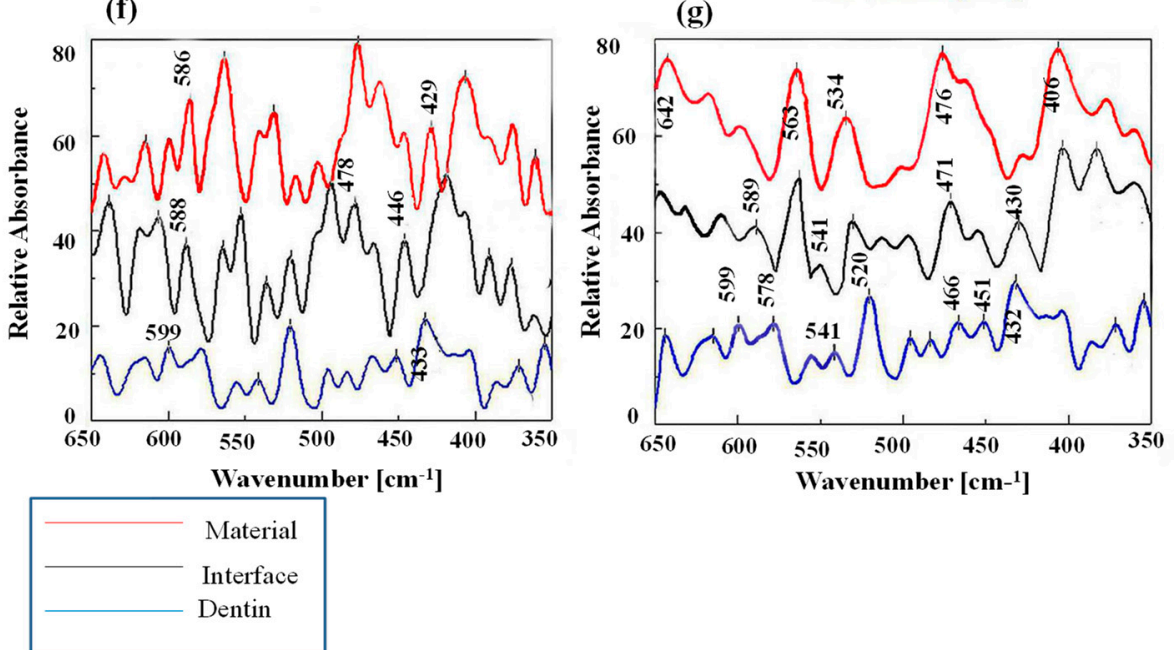

Figure 1. Raman spectra of EndoSequence fast-set putty versus regular-set paste kept in deionized water (a) or fetal calf serum (FCS) (b-g) for 28 days. Spectra include materials' surface, materials'-dentin interface, and dentin. 
After incubation in FCS for 28 days, apatitic phosphate bands were detected at the following values: $v 3 \mathrm{PO}_{4}{ }^{3-}$ at 1050, 1040, and $1030 \mathrm{~cm}^{-1} ; v 1 \mathrm{PO}_{4}{ }^{3-}$ shift around $965 \mathrm{~cm}^{-1}[16,29] ; v 4 \mathrm{PO}_{4}{ }^{3-}$ at $588 \mathrm{~cm}^{-1}$; and $\mathrm{v} 2 \mathrm{PO}_{4}{ }^{3-}$ around $430 \mathrm{~cm}^{-1}[23,28]$ (Figure $1 \mathrm{~b}-\mathrm{g}$ ). The non-apatitic phosphate band was seen around $1110 \mathrm{~cm}^{-1}$ [15]. Additionally, the spectra of the interface revealed dentin bands at 961 , 599,520 , and $430 \mathrm{~cm}^{-1}$ (Figure 1f,g).

The ratio of the $965 \mathrm{Ap} / 916 \mathrm{CaWO}_{4} \mathrm{~cm}^{-1}$ band intensity at the material-surface and the material-dentin interface of EndoSequence fast-set putty was $1.19 \pm 0.13$ and $1.31 \pm 0.11$, respectively. This was compared to the respective values of $3.26 \pm 0.35$ and $5.17 \pm 0.57$ obtained at the surface and dentin interface of the regular-set paste.

After incubation in FCS, the mineral maturity at the putty surface and interface $(1.53 \pm 0.28$ and $4.05 \pm 0.79$, respectively) was significantly $(p=0.004)$ lower than that of the paste $(12.47 \pm 5.57$ and $14.66 \pm 5.03$, respectively).

\subsection{Fourier Transform Infrared Spectroscopy}

The infrared spectra of EndoSequence fast-set putty and regular-set paste, kept in deionized water for 28 days, showed nearly identical compositions, but with little variations in band intensities (Figure 2a). The spectra were characterized by the presence of intense carbonate bands (calcite or aragonite) at 1412 and $873 \mathrm{~cm}^{-1}[6,12,20]$; however, these bands were more intense in the EndoSequence regular-set paste than in fast-set putty. The $v 3 \mathrm{PO}_{4}{ }^{3-}$ bands at 1060 and $1027 \mathrm{~cm}^{-1}[14,15,30]$ were also broad in the regular-set paste, and weak in the fast-set putty. The $v 3$ of polymerized silicate hydrate at $990 \mathrm{~cm}^{-1}$ [31], alite at 935 and $930 \mathrm{~cm}^{-1}$ [21,25,31], aluminate phase at 745 and $655 \mathrm{~cm}^{-1}$ [25,32], and calcium silicate hydrate at 506 and $445 \mathrm{~cm}^{-1}[6,21]$ was also detected for both materials. After incubation in FCS for 28 days, $\mathrm{PO}_{4}{ }^{3-}$ bands of $v 1$ around $960 \mathrm{~cm}^{-1}$, characteristic apatite twin bands of $\checkmark 4 \mathrm{PO}_{4}{ }^{3-}$ at 602 and $560 \mathrm{~cm}^{-1}$, and $v 3$ mode at $1027 \mathrm{~cm}^{-1}[23,28]$ were also detected (Figure $2 \mathrm{~b}$ ).

The EndoSequence fast-set putty showed a statistically insignificantly $(p=0.13)$ higher $\mathrm{CO}_{3} / \mathrm{PO}_{4}$ ratio $(0.38 \pm 0.05)$ than the regular-set paste $(0.32 \pm 0.07)$. However, after incubation in FCS, the $\mathrm{CO}_{3} / \mathrm{PO}_{4}$ for both materials was significantly decreased ( $0.22 \pm 0.03$ for putty and $0.27 \pm 0.01$ for paste), with no significant difference between them $(p=0.215)$.

The crystallinity index of the apatite precipitate seen on the surface of each material was $6.6 \pm 1.3$ and $4.35 \pm 0.6$ for EndoSequence fast-set putty and EndoSequence regular-set paste, respectively. There was no significant difference $(p=0.139)$ between them regarding the crystallinity index. 
(a) Materials incubated in deionized water for 28 days

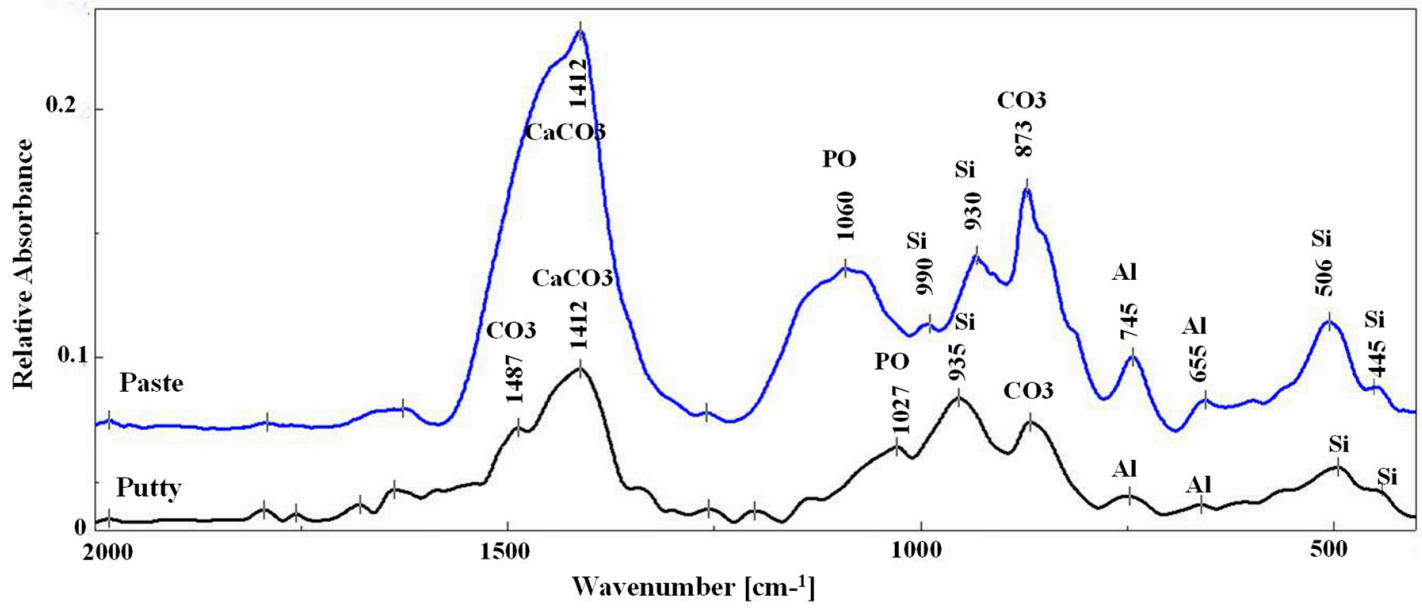

(b) Materials incubated in FCS for 28 days

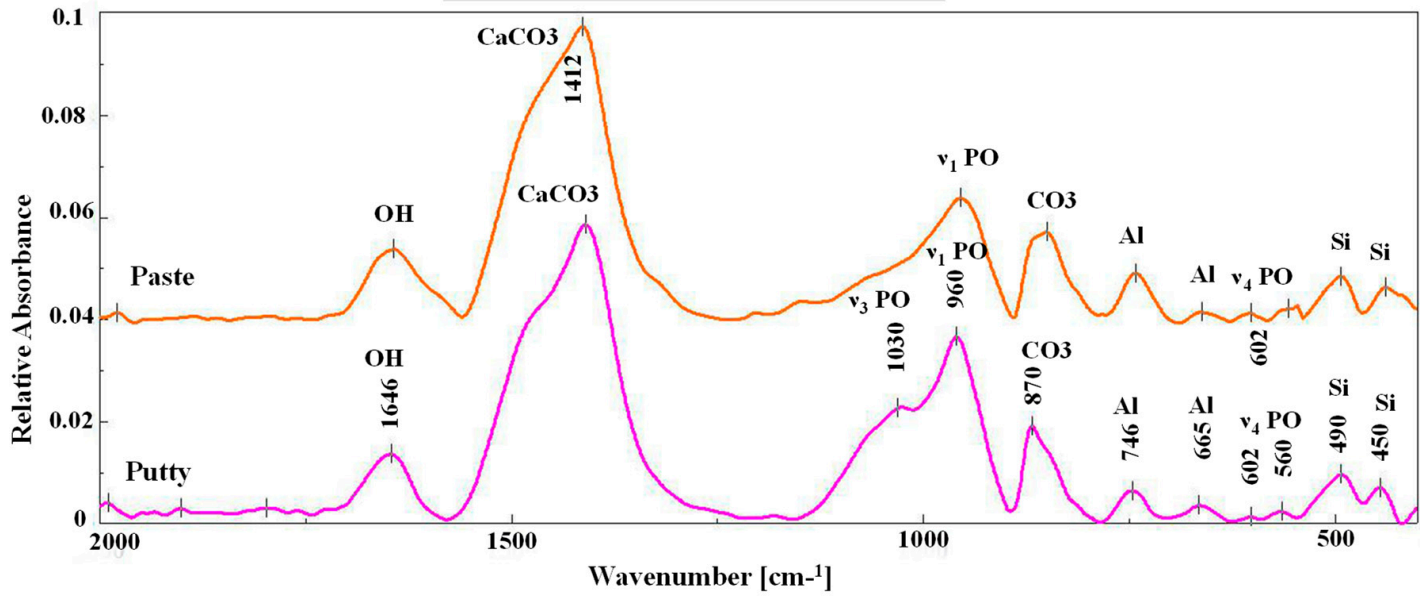

Figure 2. Fourier transform infrared spectroscopy (FTIR) spectra of EndoSequence fast-set putty and regular-set paste kept in deionized water (a) or FCS (b) for 28 days.

\subsection{Scanning Electron Microscopy/Energy Dispersed X-ray Analysis}

Figure 3 shows the SEM/EDX of EndoSequence fast-set putty and regular-set paste samples, kept in deionised water for 28 days. The surface of the EndoSequence fast-set putty had small, irregular particles (horizontal white arrows in Figure 3a,b), interrupted by small, rounded, globular crystals (horizontal black arrows in Figure $3 b, c$ ), and a few needle-like particles (vertical black arrows in Figure $3 b, c)$. A few dispersed radio-opacifier dots (vertical white arrows in Figure 3a) were also seen. At the EndoSequence putty-dentin interface, a gap was clearly identified (Figure 3d). EDX analysis revealed the presence of calcium $(\mathrm{Ca})$, oxygen $(\mathrm{O})$, carbon $(\mathrm{C})$, phosphorus $(\mathrm{P})$, zirconium $(\mathrm{Zr})$, tantalum $(\mathrm{Ta})$, silicon $(\mathrm{Si})$, and sodium $(\mathrm{Na})$, with traces of fluoride $(\mathrm{F})$, magnesium $(\mathrm{Mg})$, aluminum $(\mathrm{Al})$, and sulfur (S). The Ca/P atomic ratios were 6.58 and 7.12 for the material-surface and the material-dentin interface, respectively (Figure $3 \mathrm{e}, \mathrm{f}$ ). The surface of EndoSequence regular-set paste revealed the presence of small-sized particles and aggregates of medium-sized grains fused with the hydrogel film. Radio-opacifier dots, as well as a few scattered rod-like bundles, were also detected (Figure 3g-i). The paste-dentin interface was sealed with the material itself (Figure 3j). EDX analysis revealed a similar composition to EndoSequence fast-set putty, but with less $\mathrm{Ca}$ and more $\mathrm{P}, \mathrm{Zr}$, and $\mathrm{Ta}$. The $\mathrm{Ca} / \mathrm{P}$ atomic ratios were 2.32 and 2.83 for the material-surface and material-dentin interface, respectively (Figure 3k,1). 


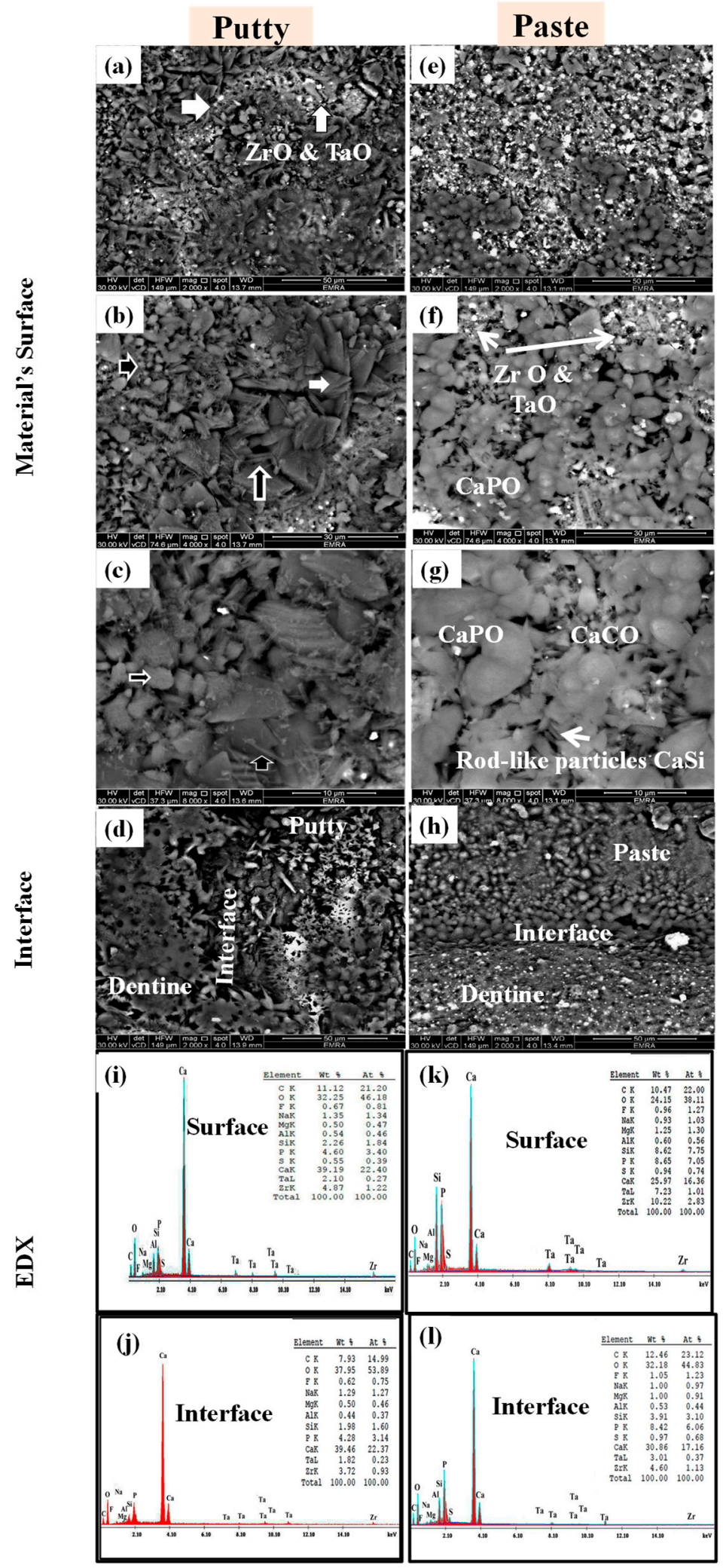

Figure 3. Scanning electron microscopy/energy dispersive X-ray (SEM/EDX) images of EndoSequence fast-set putty (a-d) versus regular-set paste (e-h) kept in deionized water for 28 days, as well as their dentin interface (i-1), respectively. (ZrO: zirconium oxide, TaO: tantalum oxide, CaPO: calcium phosphate, $\mathrm{CaCO}$ : calcium carbonate, $\mathrm{CaSi}$ : calcium silicate). Energy Dispersed X-ray detected bands of carbone (c), oxygen $(\mathrm{O})$, fluoride $(\mathrm{F})$, sodium $(\mathrm{Na})$, magnesium $(\mathrm{Mg})$ aluminum $(\mathrm{Al})$, silicon $(\mathrm{Si})$, phosphorus $(\mathrm{P})$, sulfur $(\mathrm{S})$, calcium(Ca), tantalum (Ta), and zirconium (Zr) on the surface and interface of both putty $(\mathbf{I}, \mathbf{j})$ and paste $(\mathbf{k}, \mathbf{l})$ specimens. 
Figure 4 shows the SEM/EDX of EndoSequence fast-set putty and regular-set paste samples, kept in FCS for 28 days. A homogenous layer of flower-like, medium-sized crystals (vertical white arrow in Figure $4 a, b$ ) and small-sized crystals (horizontal white arrow in Figure 4c,d) covered the entire surface of the fast-set putty and regular-set paste, respectively. Both material-dentine interfaces were filled with spherulites and acicular crystals (Figure $4 \mathrm{e}, \mathrm{f}$ ). However, the respective $\mathrm{Ca} / \mathrm{P}$ atomic ratios were 3.44 and 3.01 for material surfaces and 3.86 and 1.98 for the material-dentin interface of both fast-set putty and regular-set paste, respectively (Figure $4 \mathrm{~g}-\mathrm{j}$ ).

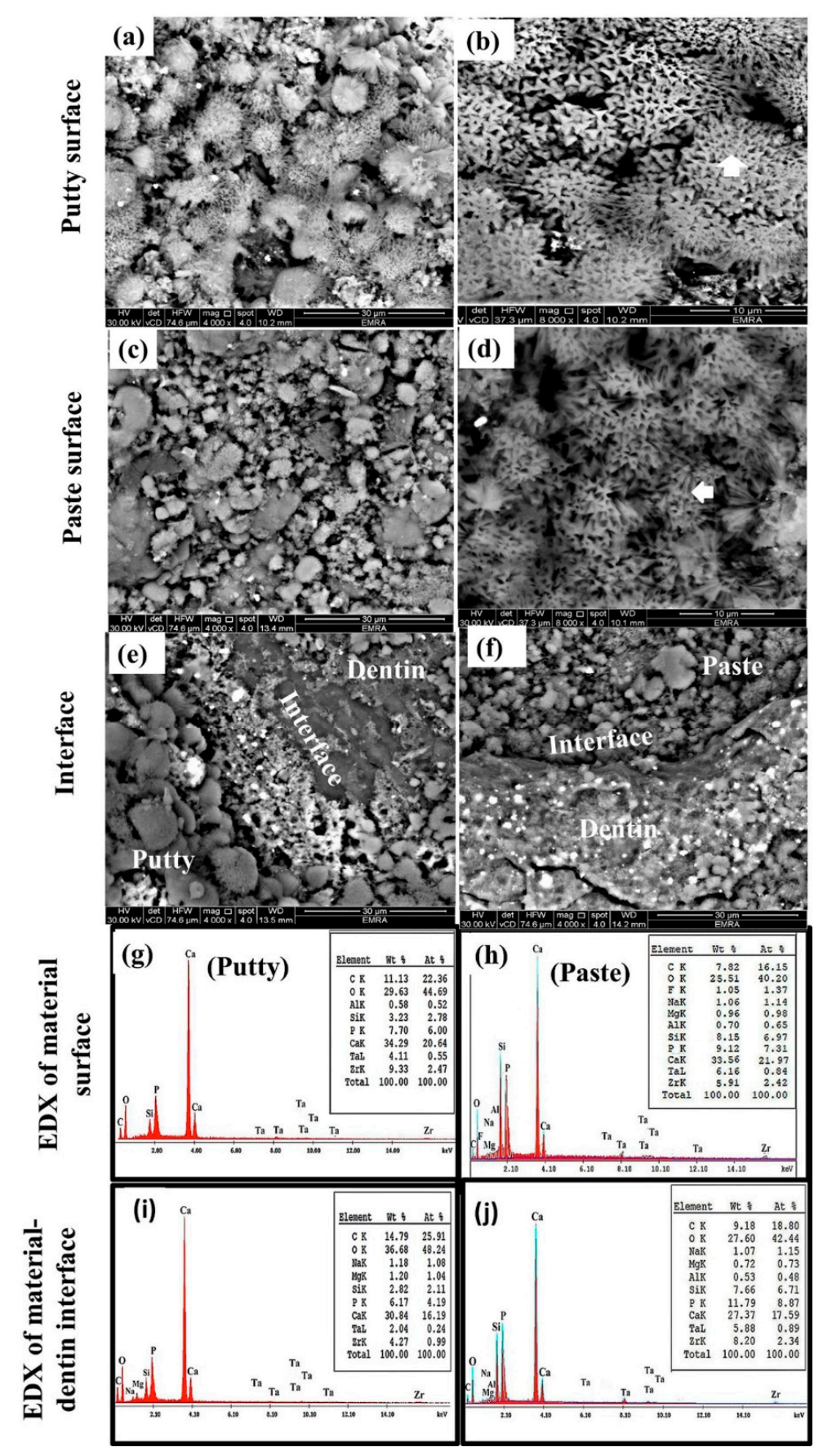

Figure 4. SEM images of EndoSequence fast-set putty $(\mathbf{a}, \mathbf{b})$ versus regular-set paste (c,d) kept in FCS for 28 days, as well as their interface with dentin $(\mathbf{e}, \mathbf{f})$, respectively. $(\mathbf{g}-\mathbf{j})$ represent the EDX data of the material-surface and material-dentin interface of fast-set putty and regular-set paste, respectively. (C: carbone, O: oxygen, F: fluoride, Na: sodium, Mg: magnesium, Al: aluminum, Si: silicon, P: phosphorus, S: sulfur, Ca: calcium, Ta: tantalum, and Zr: zirconium). 


\subsection{X-ray Diffraction Analysis}

The phase analysis revealed that the EndoSequence fast-set putty contained calcium carbonate $\left[\mathrm{CaCO}_{3}\right.$, card No: 01-070-0095], sodium silicate hydroxide hydrate [Revdite, $\mathrm{Na}_{16}\left(\mathrm{Si}_{4} \mathrm{O}_{6}(\mathrm{OH})_{5}\right)_{2}\left(\mathrm{Si}_{8} \mathrm{O}_{15}(\mathrm{OH})_{6}\right)(\mathrm{OH})_{10}\left(\mathrm{H}_{2} \mathrm{O}\right)_{28}$, card No: 01-077-0852], magnesium aluminum silicate [pyrope, $\mathrm{Mg}_{3} \mathrm{Al}_{2}\left(\mathrm{SiO}_{4}\right)_{3}$, card No: 01-083-1711], and calcium hydrogen phosphate hydrate [Ca $\left(\mathrm{H}_{2} \mathrm{PO}_{4}\right)_{2} \mathrm{H}_{2} \mathrm{O}$, card No: 01-075-1521]. Conversely, the EndoSequence regular-set paste contained calcium carbonate $\left[\mathrm{CaCO}_{3}\right.$, card No: 00-003-0893], calcium phosphate $\left[\alpha-\mathrm{Ca}_{3}\left(\mathrm{PO}_{4}\right)_{2}\right.$, card No: 00-029-0359], calcium silicate sulfate [Ternesite, $\mathrm{Ca}_{5}\left(\mathrm{SiO}_{4}\right)_{2}\left(\mathrm{SO}_{4}\right)$, card No: 01-088-0812], and sodium aluminum silicate $\left[\mathrm{Na}\left(\mathrm{AlSi}_{3} \mathrm{O}_{8}\right)\right.$, card No: 01-071-6220]. Both materials contained tantalum oxide [Tantite O11, $\mathrm{Ta}_{2} \mathrm{O}_{5}$, card No: 01-071-0639] and zirconium oxide [Baddeleyite, $\mathrm{ZrO}_{2}$, card No: 01-070-2491] (Figure 5a,b). After incubation of the specimen in FCS, additional phases of calcium phosphate hydroxide [hydroxyapatite, $\mathrm{Ca}_{5}\left(\mathrm{PO}_{4}\right)_{3}(\mathrm{OH})$; card No: 01-073-8421] and calcite $\left[\mathrm{CaCO}_{3}\right.$; card No: 01-075-4353] were observed in EndoSequence fast-set putty, while aragonite $\left[\mathrm{CaCO}_{3}\right.$; $\mathrm{card}$ No: 00-003-0893] was detected in the regular-set paste (Figure 5c,d).
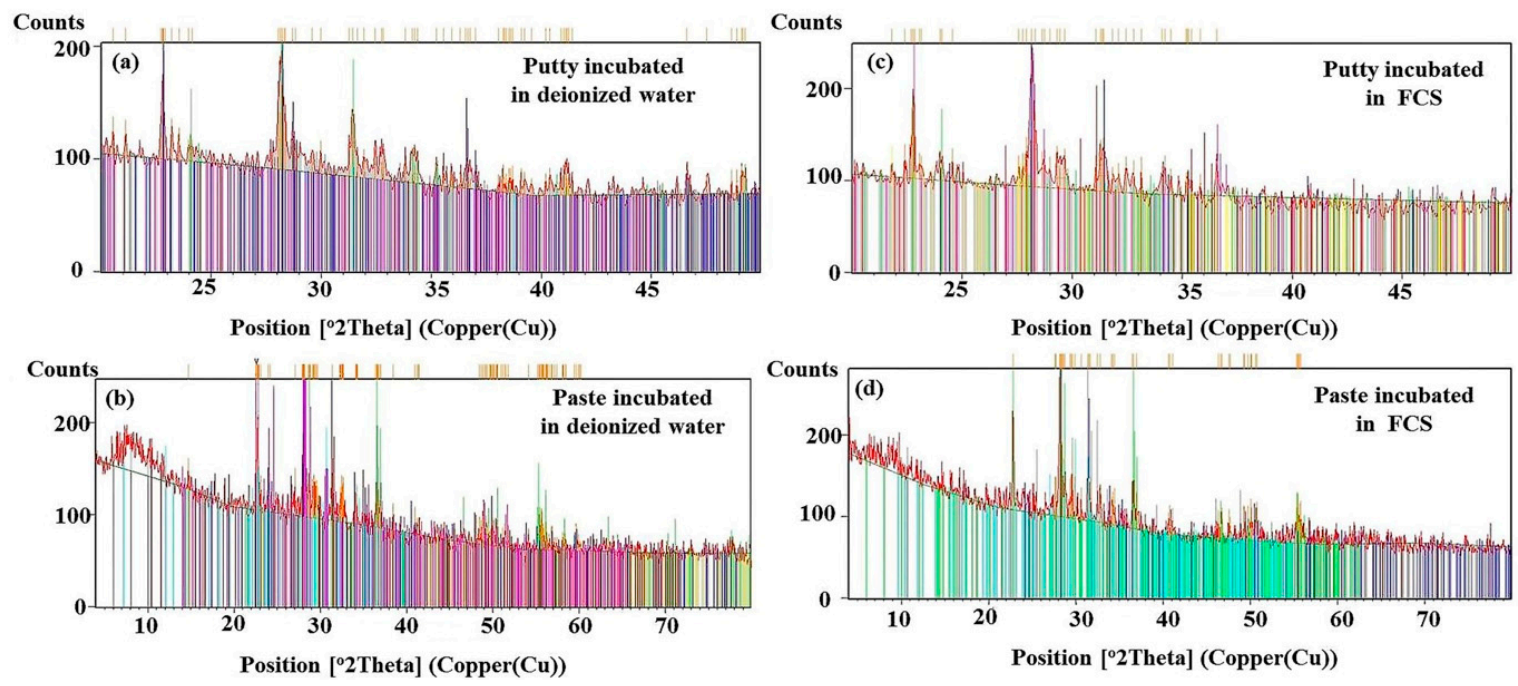

Figure 5. X-ray diffraction (XRD) pattern of fast-set putty and regular-set paste incubated in either deionized water $(\mathbf{a}, \mathbf{b})$ or FCS $(\mathbf{c}, \mathbf{d})$ for 28 days.

\section{Discussion}

This study aimed to evaluate the morphology and chemistry of an apatite layer induced by two different formulations of EndoSequence root repair material: the EndoSequence fast-set putty and regular-set paste. Apatite precipitation was detected over both materials after incubation in FCS for 28 days. Shokouhinejad et al., 2012 detected apatite precipitation on ERRM putty one week after immersion in phosphate buffer solution [9].

Raman and FTIR spectroscopy revealed that both formulations contain calcium carbonate (calcite or aragonite), silicate, phosphate, aluminum, sulfur, zirconium, and tantalum bands. However, the EndoSequence regular-set paste showed a more intense calcite band at $1412 \mathrm{~cm}^{-1}$ and a broader $v 3$ $\mathrm{PO}_{4}{ }^{3-}$ band at $1060 \mathrm{~cm}^{-1}$ compared to fast-set putty, which had a weak $v 3 \mathrm{PO}_{4}{ }^{3-}$ band at $1027 \mathrm{~cm}^{-1}$. This finding was also confirmed by XRD, which revealed that both formulations were mainly composed of calcium carbonate, calcium phosphate hydrate, zirconium oxide, and tantalum oxide. Sodium silicate hydroxide hydrate and magnesium aluminum silicate were also detected in the putty consistency, while calcium silicate sulfate and sodium aluminum silicate were detected in the paste consistency. Zamparini et al. 2018 showed a similar composition of TotalFill putty and paste; both contained calcium silicate, monobasic calcium phosphate, zirconia, tantalum peroxide, and organic components [10]. However, Moinzadeh et al. 2016 failed to detected phosphate phase in XRD [8]. The current EDX analysis showed 
that the regular-set paste consistency had a higher phosphorus, tantalum, and zirconium content, but less calcium than the fast-set putty. On the contrary, TotalFill paste showed less phosphorus, tantalum, and zirconium, but more calcium (atomic \%), than the TotalFill putty [10].

SEM revealed that the surface of both consistencies was covered with small and rounded or small and spherulite-shaped calcium phosphate particles in the putty and paste specimens, respectively. These particles were mixed with irregular, sharp-edged particles of the calcium carbonate compound; small, spheroid, globular crystals of the calcium phosphate compound; a rod-like bundle of the calcium silicate sulfate; needle-like particles of the sulfate compounds; and radio-opacifier dots of zirconium oxide and tantalum oxide [2,14].

Apatite precipitation is an important requirement for any dental filling material. This improves the adaptation and sealing properties of filling materials [28,32]. The parameters that were used to characterize the precipitated apatite layer include the following: the intensity ratio of $965 \mathrm{Ap} / 916 \mathrm{CaWO}$, mineral maturity $[14,15,21], \mathrm{CO}_{3} / \mathrm{PO}_{4}$ ratio, and crystallinity index $[13,14,18]$. In this study, the samples were kept in FCS for 28 days and compared with the control samples incubated in deionized water for the same period. XRD analysis detected hydroxyapatite and calcite in fast-set putty, while aragonite was exhibited in regular-set paste specimens.

The presence of $v 1 \mathrm{PO}_{4}{ }^{3-}$ bands at around 1030 and $965 \mathrm{~cm}^{-1}$ on the material-surface and material-dentin interface of both paste and putty materials after incubation in FCS indicates the formation of an apatite layer and hence the bioactivity of the material [3]. For samples that were incubated in deionized water, the $v 1 \mathrm{PO}_{4}{ }^{3-}$ band was originally detected at $926 \mathrm{~cm}^{-1}$ instead of $965 \mathrm{~cm}^{-1}$. The apatite crystals formed on the surface of both materials had a rosette, flower-like shape. This was confirmed by the intensity ratio of $965 \mathrm{Ap} / 916 \mathrm{CaWO}_{4}$ and area ratio of $1030 / 1110 \mathrm{~cm}^{-1}$. However, the EndoSequence regular-set paste had a higher ratio for both parameters than the EndoSequence fast-set putty. This finding might indicate that the EndoSequence regular-set paste has a thicker apatite layer with a higher mineral maturity (transformation of non-apatitic calcium phosphate into apatite calcium phosphate) than the one formed on the surface of EndoSequence fast-set putty [16]. However, the FTIR results revealed that the EndoSequence fast-set putty had a higher crystallinity index, which indicates the perfection of apatite crystals, than the EndoSequence regular-set paste $[14,30,33]$. It was also revealed that the apatite layer formed on the surface of EndoSequence fast-set putty $(\mathrm{Ca} / \mathrm{P}=3.44)$ and the putty-dentin interface $(\mathrm{Ca} / \mathrm{P}=3.86)$ had a higher $\mathrm{Ca} / \mathrm{P}$ ratio than that of the EndoSequence regular-set paste $(\mathrm{Ca} / \mathrm{P}=3.01,1.89$ respectively). Because the $\mathrm{Ca} / \mathrm{P}$ ratio obtained in this study is higher than that of hydroxyapatite $(\mathrm{Ca} / \mathrm{P}=1.67)$, the precipitates seen on the surface of the studied formulations could be a combination of hydroxyapatite and calcite or aragonite $[6,16,20,34]$. This was also confirmed by XRD. Because the precipitate seen on the surface of the EndoSequence fast-set putty had a higher $\mathrm{Ca} / \mathrm{P}$ ratio than that of the EndoSequence regular-set paste, the amount of calcite or aragonite in this precipitate could also be higher than that of the paste formulation.

It was also observed that the surface and interface of EndoSequence fast-set putty and regular-set paste had different parameters (965Ap/916CaWO4, mineral maturity, CO3/PO4, crystallinity index, and $\mathrm{Ca} / \mathrm{P}$ ) than those recorded after storage in FCS for 28 days. This finding suggests that the surface of both formulations was entirely covered with the precipitated apatite layer.

\section{Conclusions}

FCS incubation affects the surface morphology and chemistry of EndoSequence fast-set putty and regular-set paste root repair materials. It provides the formation of a uniform layer of flower-like crystals, which covered the entire material's surface and the material-dentin interface in this study. Spherulites and acicular crystals were also seen at the interface. These results suggest that the precipitate is a combination of hydroxyapatite and calcite or aragonite. The EndoSequence regular-set paste had a higher mineral maturity than the EndoSequence fast-set putty. Conversely, the apatite layer seen on the EndoSequence fast-set putty had a higher crystallinity index than that of the EndoSequence regular-set paste. Consequently, both consistencies (putty and paste) of root repair material can be 
considered bioactive, i.e., they have an apatite formation ability when incubated in fetal calf serum, and this could be beneficial in improving the sealing ability of these materials.

Author Contributions: Conceptualization, S.T.A.Z.; data curation, S.T.A.Z.; formal analysis, S.T.A.Z.; funding acquisition, S.T.A.Z., R.A.A., and A.A.M.S.; investigation, S.T.A.Z., R.A.A., E.A.A.N., and A.A.M.S.; project administration, S.T.A.Z. and R.A.A.; methodology, S.T.A.Z., R.A.A., E.A.A.N., and A.A.M.S.; resources, S.T.A.Z., R.A.A., E.A.A.N., and A.A.M.S.; software: S.T.A.Z.; supervision, S.T.A.Z. and R.A.A.; validation, S.T.A.Z.; writing—original draft, S.T.A.Z. and E.A.A.N.; writing一review and editing, S.T.A.Z., R.A.A., E.A.A.N., and A.A.M.S.

Funding: This research received no external funding.

Conflicts of Interest: The authors declare no conflicts of interest.

\section{References}

1. Parirokh, M.; Torabinejad, M. Mineral trioxide aggregate: A comprehensive literature review-Part III: Clinical applications, drawbacks, and mechanism of action. J. Endod. 2010, 36, 400-413. [CrossRef] [PubMed]

2. Roberts, H.W.; Toth, J.M.; Berzins, D.W.; Charlton, D.G. Mineral trioxide aggregate material use in endodontic treatment: A review of the literature. Dent. Mater. 2008, 24, 149-164. [CrossRef] [PubMed]

3. Main, C.; Mirzayan, N.; Shabahang, S.; Torabinejad, M. Repair of root perforations using mineral trioxide aggregate: A long-term study. J. Endod. 2004, 30, 80-83. [CrossRef] [PubMed]

4. Abu Zeid, S.; Saleh, A.M.; Khafagi, M.; Neel, E.A. Setting Reaction of New Bioceramic Root Canal Sealers. Spectrosc. Lett. 2018, 51, 426-430. [CrossRef]

5. Han, L.; Okiji, T.; Okawa, S. Morphological and chemical analysis of different precipitates on mineral trioxide aggregate immersed in different fluids. Dent. Mater. J. 2010, 29, 512-517. [CrossRef] [PubMed]

6. Gandolfi, M.G.; Taddei, P.; Tinti, A.; Prati, C. Apatite-forming ability (bioactivity) of ProRoot MTA. Int. Endod. J. 2010, 43, 917-929. [CrossRef]

7. Alamoudi, R.A.; Abu Zeid, S.T. Effect of Irrigants on the Push-Out Bond Strength of Two Bioceramic Root Repair Materials. Materials 2019, 12, 1921. [CrossRef]

8. Moinzadeh, A.T.; Portoles, C.A.; Wismayer, P.S.; Camilleri, J. Bioactivity potential of EndoSequence BC RRM putty. J. Endod. 2016, 42, 615-621. [CrossRef]

9. Shokouhinejad, N.; Nekoofar, M.H.; Razmi, H.; Sajadi, S.; Davies, T.E.; Saghiri, M.A.; Gorjestani, H.; Dummer, P.M.H. Bioactivity of EndoSequence root repair material and bioaggregate. Int. Endod. J. 2012, 45, 1127-1134. [CrossRef]

10. Zamparini, F.; Siboni, F.; Prati, C.; Taddei, P.; Gandolfi, M.G. Properties of calcium silicate-monobasic calcium phosphate materials for endodontics containing tantalum pentoxide and zirconium oxide. Clinl. Oral. Investig. 2018, 23, 445-457. [CrossRef]

11. Tingey, M.C.; Bush, P.; Levine, M.S. Analysis of mineral trioxide aggregate surface when set in the presence of fetal bovine serum. J. Endod. 2008, 34, 45-49. [CrossRef]

12. Gandolfi, M.G.; Ciapetti, G.; Taddei, P.; Perut, F.; Tinti, A.; Cardoso, M.V.; Van Meerbeek, B.; Prati, C. Apatite formation on bioactive calcium-silicate cements for dentistry affects surface topography and human marrow stromal cells proliferation. Dent. Mater. 2010, 26, 974-992. [CrossRef] [PubMed]

13. Abu Zeid, S.T.; Alamoudi, N.M.; Khafagi, M.G.; Abou Neel, E.A. Chemistry and Bioactivity of NeoMTA Plus $^{\mathrm{TM}}$ versus MTA Angelus ${ }^{\circledR}$ Root Repair Materials. J. Spectrosc. 2017, 2017, 8736428. [CrossRef]

14. Farlay, D.; Panczer, G.; Rey, C.; Delmas, P.D.; Boivin, G. Mineral maturity and crystallinity index are distinct characteristics of bone mineral. J. Bone Miner. Metab. 2010, 28, 433-445. [CrossRef] [PubMed]

15. Sauer, G.; Zunic, W.; Durig, J.; Wuthier, R. Fourier transform Raman spectroscopy of synthetic and biological calcium phosphates. Calcif. Tissue Int. 1994, 54, 414-420. [CrossRef] [PubMed]

16. Siboni, F.; Taddei, P.; Zamparini, F.; Prati, C.; Gandolfi, M.G. Properties of BioRoot RCS, a tricalcium silicate endodontic sealer modified with povidone and polycarboxylate. Int. Endod. J. 2017, 50, e120-e136. [CrossRef] [PubMed]

17. Tesch, W.; Eidelman, N.; Roschger, P.; Goldenberg, F.; Klaushofer, K.; Fratzl, P. Graded microstructure and mechanical properties of human crown dentin. Calcif. Tissue Int. 2001, 69, 147-157. [CrossRef] 
18. Notingher, I.; Jones, J.; Verrier, S.; Bisson, I.; Embanga, P.; Edwards, P.; Polak, J.; Hench, L. Application of FTIR and Raman spectroscopy to characterisation of bioactive materials and living cells. J. Spectrosc. 2003, 17, 275-288. [CrossRef]

19. Frost, R.L. Raman spectroscopic study of the magnesium carbonate mineral hydromagnesite $\left(\mathrm{Mg}_{5}\left[\left(\mathrm{CO}_{3}\right)_{4}(\mathrm{OH})_{2}\right] \cdot 4 \mathrm{H}_{2} \mathrm{O}\right)$. J. Raman Spectrosc. 2011, 42, 1690-1694. [CrossRef]

20. Gandolfi, M.G.; Taddei, P.; Siboni, F.; Modena, E.; Ginebra, M.P.; Prati, C. Fluoride-containing nanoporous calcium-silicate MTA cements for endodontics and oral surgery: Early fluorapatite formation in a phosphate-containing solution. Int. Endod. J. 2011, 44, 938-949. [CrossRef]

21. Taddei, P.; Modena, E.; Tinti, A.; Siboni, F.; Prati, C.; Gandolfi, M.G. Vibrational investigation of calcium-silicate cements for endodontics in simulated body fluids. J. Mol. Struct. 2011, 993, 367-375. [CrossRef]

22. Taddei, P.; Tinti, A.; Gandolfi, M.G.; Rossi, P.L.; Prati, C. Ageing of calcium silicate cements for endodontic use in simulated body fluids: A micro-Raman study. J. Raman Spectrosc. 2009, 40, 1858-1866. [CrossRef]

23. Gandolfi, M.G.; Van Landuyt, K.; Taddei, P.; Modena, E.; Van Meerbeek, B.; Prati, C. Environmental scanning electron microscopy connected with energy dispersive X-ray analysis and Raman techniques to study ProRoot mineral trioxide aggregate and calcium silicate cements in wet conditions and in real time. J. Endod. 2010, 36, 851-857. [CrossRef] [PubMed]

24. Turunen, M.J.; Saarakkala, S.; Rieppo, L.; Helminen, H.J.; Jurvelin, J.S.; Isaksson, H. Comparison between infrared and Raman spectroscopic analysis of maturing rabbit cortical bone. Appl. Spectrosc. 2011, 65, 595-603. [CrossRef] [PubMed]

25. Khan, A.S.; Khalid, H.; Sarfraz, Z.; Khan, M.; Iqbal, J.; Muhammad, N.; Fareed, M.A.; Rehman, I.U. Vibrational spectroscopy of selective dental restorative materials. Appl. Spectrosc. Rev. 2017, 52, 507-540. [CrossRef]

26. Chen, Y.; Fierro, J.L.; Tanaka, T.; Wachs, I.E. Supported tantalum oxide catalysts: Synthesis, physical characterization, and methanol oxidation chemical probe reaction. J. Phys. Chem. B 2003, 107, 5243-5250. [CrossRef]

27. Siboni, F.; Taddei, P.; Prati, C.; Gandolfi, M. Properties of Neo MTA Plus and MTA Plus cements for endodontics. Int. Endod. J. 2017, 50, e83-e94. [CrossRef]

28. Timchenko, P.E.; Timchenko, E.V.; Pisareva, E.V.; Vlasov, M.Y.; Red'kin, N.A.; Frolov, O.O. Spectral Analysis of Allogeneic Hydroxyapatite Powders. J. Phys. Conf. Ser. 2017. [CrossRef]

29. Ciobotă, V.; Salama, W.; Jentzsch, P.V.; Tarcea, N.; Rösch, P.; El Kammar, A.; Morsy, R.S.; Popp, J. Raman investigations of upper cretaceous phosphorite and black shale from Safaga District, Red Sea, Egypt. Spectrochim. Acta Part A: Mol. Biomol. Spectrosc. 2014, 118, 42-47. [CrossRef]

30. Ribeiro, T.J.; Lima, O.J.; Faria, E.H.; Rocha, L.A.; Calefi, P.S.; Ciuffi, K.J.; Nassar, E.J. Sol-gel as methodology to obtain bioactive materials. Ann. Acad. Bras. Ciê 2014, 86, 27-36. [CrossRef]

31. Singh, N.B.; Das, S.S.; Singh, N.P.; Dwivedi, V.N. Studies on SCLA composite Portland cement. Indian J. Eng. Mater. Sci. 2009, 16, 415-422.

32. Gandolfi, M.G.; Taddei, P.; Modena, E.; Siboni, F.; Prati, C. Biointeractivity-related versus chemi/physisorption-related apatite precursor-forming ability of current root end filling materials. J. Biomed. Mater. Res. Part B: Appl. Biomater. 2013, 101, 1107-1123. [CrossRef] [PubMed]

33. Berzina-Cimdina, L.; Borodajenko, N. Research of calcium phosphates using Fourier transform infrared spectroscopy. In Infrared Spectroscopy-Materials Science, Engineering and Technology; InTech: Rijeka, Croatia, 2012; pp. 251-263.

34. Best, S.; Porter, A.; Thian, E.; Huang, J. Bioceramics: Past, present and for the future. J. Eur. Ceram. Soc. 2008, 28, 1319-1327. [CrossRef]

(C) 2019 by the authors. Licensee MDPI, Basel, Switzerland. This article is an open access article distributed under the terms and conditions of the Creative Commons Attribution (CC BY) license (http://creativecommons.org/licenses/by/4.0/). 